\title{
Sir Charles Locock and potassium bromide
}

\author{
MJ Eadie \\ Honorary Research Consultant and Emeritus Professor, Faculty of Health Sciences, University of Queensland, Royal Brisbane and \\ Women's Hospital, Australia
}

\begin{abstract}
On 12 May 1857, Edward Sieveking read a paper on epilepsy to the Royal Medical and Chirurgical Society in London. During the discussion that followed Sir Charles Locock, obstetrician to Queen Victoria, was reported to have commented that during the past 14 months he had used potassium bromide to successfully stop epileptic seizures in all but one of 14 or 15 women with 'hysterical' or catamenial epilepsy. This report of Locock's comment has generally given him credit for introducing the first reasonably effective antiepileptic drug into medical practice. However examination of the original reports raises questions as to how soundly based the accounts of Locock's comments were. Subsequently, others using the drug to treat epilepsy failed to obtain the degree of benefit that the reports of Locock's comments would have led them to expect. The drug might not have come into more widespread use as a result, had not Samuel Wilks provided good, independent evidence for the drug's antiepileptic efficacy in I86I.
\end{abstract}

\author{
Correspondence to M Eadie \\ Faculty of Health Sciences, \\ University of Queensland, \\ Royal Brisbane and Women's \\ Hospital, Herston, \\ Brisbane 4029, Australia
}

Tel 6 I 2 (0)7 383 III704 e-mail M.Eadie@uq.edu.au

KEYWORDS Epilepsy treatment, Charles Locock, potassium bromide, Edward Sieveking, Samuel Wilks

DECLARATIONS OF INTERESTS No conflicts of interest declared.

\section{INTRODUCTION}

Potassium bromide was the first even modestly effective agent for preventing epileptic seizures to emerge from a search of more than two thousand years. It is often stated that the drug was introduced into antiepileptic therapeutics by Sir Charles Locock in 1857. Enough detail of the circumstances of Locock's recognition of the antiepileptic activity of the substance has been published over the years since then ${ }^{1-4}$ to make any further account unnecessary, had it not been for several peculiar details which seem to have been overlooked.

\section{SIR CHARLES LOCOCK (1799-I875)}

Several accounts of Locock's life are available. ${ }^{5-8}$ Charles Locock (Figure I) was born in Northampton on 2I April 1799 to Henry Locock, a medical practitioner and his first wife Susanna, née Smythe. He studied at St George's Hospital in London before graduating MD from Edinburgh University in 1821. He became a Licentiate of the Royal College of Physicians of London in 1823 and gained experience at the Westminster Lying-in Hospital in London before commencing consulting practice in midwifery in that city. In 1826 Locock married Amelia Lewis, who predeceased him. The couple had five sons. He built up a very large and successful practice and became Physician to the Westminster Lying-in Hospital, lectured on midwifery at St Bartholomew's Hospital and in 1836 was elected Fellow of the Royal College of

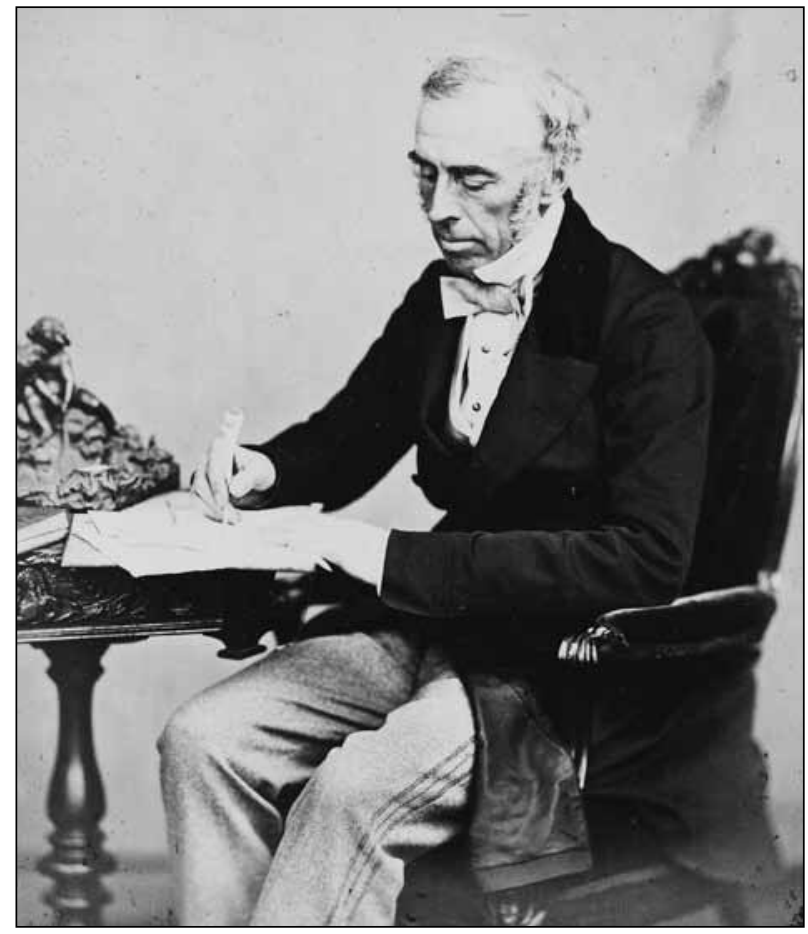

FIGURE I Sir Charles Locock. Reproduced with kind permission of the Wellcome Library, London.

Physicians (RCP). He served as a member of the RCP Council between 1840 and 1842. In 1840 Locock was appointed First Physician Accoucheur to Queen Victoria and was in attendance at the births of all of her children. He retired from practice in 1857 , having been created a 
baronet in that year when he also became President of the Royal Medical and Chirurgical Society. In 1863 he was President of the Obstetrical Society of London and in I864 was elected to Fellowship of the Royal Society. During his retirement he unsuccessfully attempted to enter politics.

Locock made a few contributions to the medical literature early in his professional career, but otherwise was notable in his lifetime mainly for his obstetric expertise and his role in relation to the British Royal Family.

\section{LOCOCK'S USE OF POTASSIUM BROMIDE IN EPILEPSY}

Curiously, Locock never published his own account of his discovery of the antiepileptic efficacy of potassium bromide. His statement about the drug's effectiveness in treating epilepsy appeared in reports of a meeting of the Royal Medical and Chirurgical Society held in London on Tuesday 12 May 1857. The reports were published on 23 May in The Lancet ${ }^{9}$ and the Medical Times and Gazette. ${ }^{10}$ Locock had chaired the meeting at which Dr (later Sir) Edward Sieveking (1816-1904) presented an analysis of 52 cases of epilepsy. Following Sieveking's presentation and comments from three members of the audience, Locock spoke from the chair before Sieveking made his concluding response. Locock was reported to have pointed out that Sieveking had failed to mention two frequent causes of epilepsy, infantile epilepsy related to dentition and epilepsy due to sexual indulgence, particularly 'onanism' i.e. masturbation. He then spoke of 'hysterical epilepsy', a disorder limited to women in which seizures occurred consistently and exclusively at the time of menstruation (except in instances of 'extreme mental excitement'). Locock stated that he had read in the British and Foreign Medical Review of a German worker who had rendered himself and others reversibly impotent when taking potassium bromide. This report had prompted Locock to prescribe it for women who experienced 'a great deal of sexual excitement and disturbance' around their times of menstruation and he observed that the drug produced very marked calming. About 14 months prior to May 1857 he had also prescribed potassium bromide for a woman with a nineyear history of 'hysterical epilepsy'. Her seizures ceased and she remained seizure-free while continuing the treatment. Locock then used the drug in another 13 or I4 cases, with only one failure, in a woman whose 'fits' were not exclusively menstrual in their timing. The Lancet account lacked this information about the sole treatment failure.

Neither journal reported that Sieveking's concluding response had mentioned Locock's extraordinarily successful therapeutic result (a greater than 93\% seizure control rate) which strongly suggested that a new highly effective antiepileptic agent might have been discovered. This seems a strange omission by Sieveking (or the reporter) when only minutes earlier he had 'expressed his belief that no specific treatment for epilepsy existed'.

\section{POTASSIUM BROMIDE BEFORE LOCOCK}

The literature from France contains at least two accounts of the early history of the use of potassium bromide in medicine. ${ }^{11,12}$ The element bromine was isolated from salt water by the Marseille chemist Antoine Balard in 1826 and potassium bromide was synthesised soon afterwards. Ricord and Puche tried it as an alternative to potassium iodide in treating secondary and tertiary syphilis but it was not successful. ${ }^{13}$ In his 1842 thesis, Otto $\mathrm{Graf}^{14}$ reported that he had become impotent while taking 600 milligrams $(\mathrm{mg})$ of the drug three times a day for two weeks and recovered sexual function after drug intake ended. This report was probably the origin of the journal report that induced Locock to prescribe the drug. Charles Huette noted that potassium bromide intake produced more or less complete torpor of the genital organs and insensitivity of the palate and pharynx, as well as general stupefaction. ${ }^{13}$ Thielman employed local applications of the substance to treat priapism. ${ }^{15}$

Potassium bromide was listed in the British Pharmacopoeia between 1835 and $185 \mathrm{I}$, curiously as a treatment for splenomegaly, but was found to lack efficacy. ${ }^{16}$ In London Robert Bentley Todd employed it in a patient with epileptic seizures in 1852, several years before Locock used it. ${ }^{17}$ Todd's patient had gout secondary to leadinduced nephropathy, was in terminal renal failure and died too soon after commencing bromide intake to permit conclusions regarding its efficacy. Todd did not indicate his rationale for using the drug.

Thus even before Locock used potassium bromide a reasonable amount of scientific work had already been done with the drug, not least by Graf and Huette. and it had been employed therapeutically for various indications, including epileptic seizures, on at least one occasion.

\section{POTASSIUM BROMIDE IMMEDIATELY AFTER LOCOCK}

There is no evidence that Locock did further work with potassium bromide after 1857. Over the next few years some of Locock's London colleagues indicated that they knew of his reported use of the drug and mentioned their own. In 1858, in the first edition of his monograph on epilepsy, Sieveking mentioned that he had prescribed potassium bromide but did not have enough results to 
justify an opinion about it..$^{18}$ In the same year Charles Bland Radcliffe stated that he had used potassium bromide once, in a woman with 'erotic excitement' and regularly occurring seizures. ${ }^{19}$ She went 5 I days without seizures before the attacks recurred. In I86I John Russell Reynolds wrote that he had prescribed potassium bromide perimenstrually in women whose epilepsy worsened at the times of menstruation, without much success. ${ }^{20}$ However, he had seen no woman with epilepsy that occurred solely at the time of menses in whom he could try the drug. Reynolds was probably unaware that potassium bromide has an elimination half-life of 12 days so it is unlikely that he employed the drug continuously for long enough to achieve adequate steady-state therapeutic conditions in his patients. ${ }^{21}$ In the same year, in the second edition of his monograph, Sieveking stated that he had used potassium bromide for the same indications as Locock, but without the same degree of success, though he considered the drug 'decidedly beneficial'. He provided no numerical data to support this opinion.

The outcome of this early British experience of the use of potassium bromide in epilepsy by three London physicians, all shortly to become members of the staff of the recently opened Hospital for the Palsied and Epileptic at Queen Square, seems not to have been particularly encouraging. The drug's use, at least at first, was largely restricted to cases of perimenstrual epilepsy, the disorder that Locock was reported to have treated so successfully. It seems likely that the drug might have disappeared from use at that stage had it been employed solely in these cases. However, beginning probably in London in 1859 and at first in ignorance of Locock's reported data, ${ }^{22}$ Samuel Wilks (Figure 2), physician and pathologist to Guy's Hospital and later President of the Royal College of Physicians of London, began to use potassium bromide to treat all forms of epilepsy. He published his results in the Medical Times and Gazette on 21 December 1861 in a paper which provided details of his individual patient case records. ${ }^{23}$ Wilks explained that he had been using potassium iodide to treat epilepsy when he thought it might be of syphilitic origin. Since he had difficulty in recognising such instances clinically, he began to try the iodide in all cases of epilepsy. He later tried potassium bromide as an alternative to the iodide because it produced better results in treating goitre and glandular swellings. Wilks observed that the bromide was much more effective than the iodide in controlling epilepsy and concluded that it must possess genuine intrinsic antiepileptic rather than simply antiinflammatory properties. ${ }^{22,24}$ Once he realised this, from March 1860 onwards he seems to have prospectively collected case material for future publication. Of his 12 reported cases, I I were treated with potassium bromide. In all but one of these, seizures either became less frequent, or ceased.

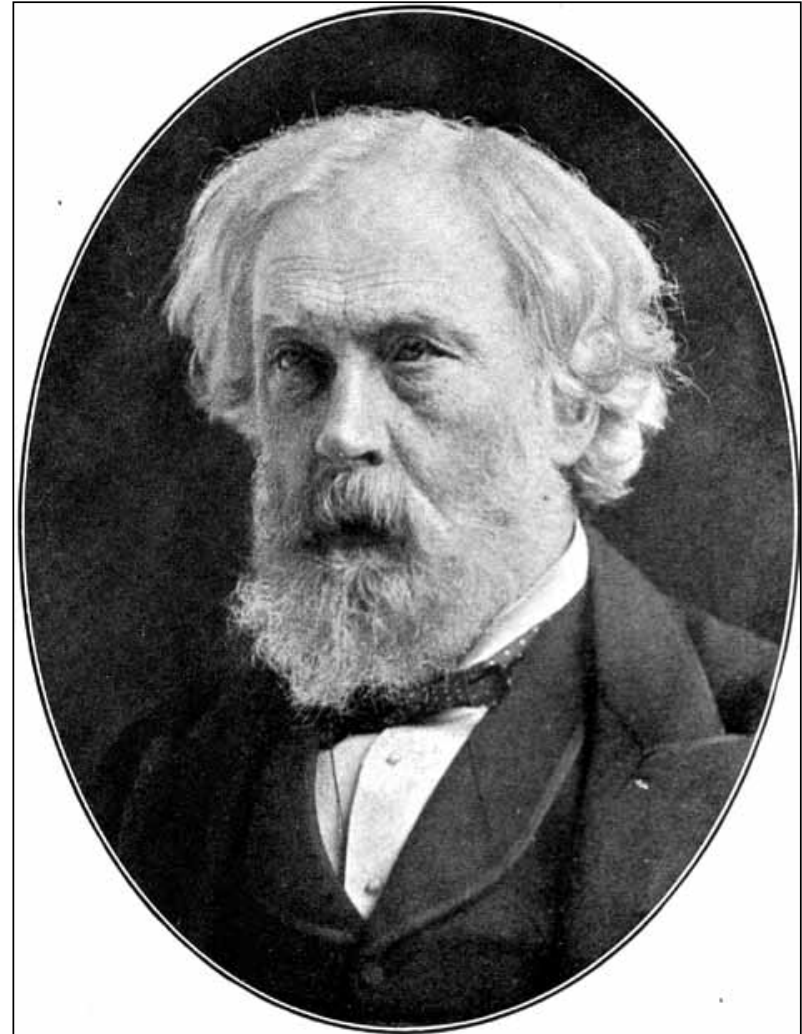

FIGURE 2 Sir Samuel Wilks, from a photograph taken in $1884 .{ }^{45}$

After Wilks' publication, reports of the use of potassium bromide in all varieties of epilepsy appeared in increasing numbers. Charles Radcliffe reported that he had employed the drug in five or six cases where uterine 'irritation' was prominent, with satisfactory results overall. ${ }^{25} \mathrm{He}$ also mentioned that, at least as early as 1860 , he had begun to use the drug 'almost promiscuously' and claimed to have records of 30 cases in whom he had compared the use of potassium with iron bromide, preferring the former, which he considered the best available remedy. ${ }^{26}$ It is difficult to know whether awareness of Wilks' work stimulated Radcliffe's 'almost promiscuous' prescribing of potassium bromide, or whether Radcliffe independently realised that potassium bromide had a wider spectrum of antiepileptic effect than the reports of Locock's finding suggested. As London physicians of the time often attended Wilks' demonstrations of pathology at Guy's Hospital, it is possible that Radcliffe was alerted to the effects of potassium bromide at one of these events.

In 1864 Rogers $^{27}$ reported using potassium bromide successfully in two cases of epilepsy (one a male) and in the same year M'Donnell ${ }^{28}$ described only one failure when treating five women with perimenstrual epilepsy.A year later, Williams found that fewer seizures occurred in asylum patients of both sexes over a five-month period of potassium bromide intake after an initial fivemonth baseline period of recording seizure frequency. ${ }^{29}$ 
Thus Wilks' I86I report was published after an initial period in which potassium bromide fell short of the expectations raised by the reports of Locock's remarks and before a subsequent period in which the drug found a very useful place in treating all types of epilepsy. Medical authorities began to testify to its usefulness as an antiepileptic agent. ${ }^{30-33}$ But it could however be addictive; by the end of the nineteenth century the Hospital for the Palsied and Epileptic in London was buying nearly two tons of the chemical annually. ${ }^{16}$

\section{DISCUSSION}

Sir Charles Locock undeniably played the leading role in recognising the first effective antiepileptic chemical agent known to medicine. However several peculiar features of the reports of his account of the matter remain to be explained.

\section{Why didn't Locock publish his own account of his discovery?}

Previous authors have noted this omission without explanation. Locock must have been aware of the importance of his finding though he may not have appreciated its full potential. Moments before he announced it, he had heard Sieveking say that no specific treatment for epilepsy was known. If what was reported was correct, Locock must have realised that he had found such a treatment, even if its benefits applied only in a particular variety of the disorder. Perhaps he subsequently felt (correctly as events proved) that what was in print in The Lancet and the Medical Times and Gazette would suffice to establish his achievement. In 1857 he was deliberately bringing his professional activities to an end, with his reputation secure and his achievements acknowledged with a baronetcy and Royal favour. His interest in medicine may have been waning. $\mathrm{He}$ had not contributed to the medical literature for many years and he may have concluded that it was not worth his while to prepare a report setting down his findings when brief versions provided by others were already in print.

\section{Were Locock's reported data correct?}

There were reports of Sieveking's paper and of what Locock said to the members of the Royal Medical and Chirurgical Society in both The Lancet and the Medical Times and Gazette. The accounts of Sieveking's paper were identical in each journal. The explanation for these two matching accounts is probably that, after a paper was submitted to the Royal Medical and Chirurgical Society for publication, the Society's Secretary was required to prepare an abstract of the paper. After approval by the President, this abstract was submitted to two referees. If they recommended acceptance of the paper, the abstract was made available to various medical journals for publication in their pages, but only after the paper had been read to the Society and on condition that the full abstract was printed unaltered. ${ }^{34}$ MedicoChirurgical Transactions published a more extensive account of Sieveking's paper than that which appeared in the other two medical journals..$^{35}$ In all probability, Locock had seen the abstract and perhaps the text of the full paper before the meeting. This would have enabled him to prepare his comments.

The accounts in The Lancet and the Medical Times and Gazette of the discussion that followed Sieveking's lecture differ in wording and in minor details, but the major facts are similar. However, Sieveking's concluding comments in the two journals are quite different. It is possible that one reporter attended Sieveking's lecture but prepared different versions of the discussion for the two journals. Alternatively two independent reporters could have been involved. This can't be confirmed.

\section{How did Locock collect so many cases of 'hysterical epilepsy'?}

Both journal accounts agree that Locock appears to have been able to collect data in either 14 or 15 cases of 'hysterical epilepsy' between March 1856 and May 1857 and also to have had time to evaluate the effects of potassium bromide therapy in all of them. This suggests a recruitment rate of just over one case per month. The plausibility of these occurrences must be questioned. The account in the Medical Times and Gazette indicated that 'hysterical epilepsy' referred to epilepsy in which seizures occurred exclusively at the time of the menstrual period (except in the case of 'great mental excitement'). More modern reported prevalence rates of catamenial epilepsy vary widely. ${ }^{36}$ Duncan et al. found that $78 \%$ of 40 women with refractory epilepsy reported that most of their seizures occurred around their times of menstruation. ${ }^{37}$ However, the seizure diaries of these women showed that only $12.5 \%$ had at least three quarters of their seizures during their ten perimenstrual days. Much published information on the frequency of catamenial epilepsy is probably suspect. Locock, an obstetrician rather than a physician, accumulated 14 or 15 instances of patients with epilepsy and catamenial epilepsy in particular, in a little over a year. Only three years later, the scientific physician and pathologist Samuel Wilks, also in London, could collect only II cases of all forms of epilepsy (six female) over 18 months for treatment with bromide. ${ }^{23}$ John Russell Reynolds, with a predominantly neurological practice in London did not find a single instance of exclusively menstrual epilepsy between 1857 and 186I, despite the fact that about half of his practice involved convulsive disease and about one third, idiopathic epilepsy. ${ }^{19}$ Perhaps Locock had used 
TABLE I Response of epileptic seizures to bromide therapy reported in various published case series. Prior to 1870 the only bromide used in these series was that of potassium.

\begin{tabular}{|c|c|c|c|c|c|c|}
\hline Author & $\begin{array}{c}\text { Number of } \\
\text { subjects }\end{array}$ & Female (\%) & $\begin{array}{l}\text { Seizure } \\
\text { free (\%) }\end{array}$ & $\begin{array}{l}\text { With fewer } \\
\text { seizures (\%) }\end{array}$ & $\begin{array}{c}\text { Not } \\
\text { improved (\%) }\end{array}$ & $\begin{array}{c}\text { Follow-up } \\
\text { duration }\end{array}$ \\
\hline Locock I8579,10 & 14 or 15 & 100 & 93 & 0 & 7 & $<14$ months \\
\hline Wilks $186 I^{23}$ & 11 & 55 & 55 & 36 & 9 & $<20$ months \\
\hline M'Donnell I864 ${ }^{28}$ & 5 & 80 & - & - & 20 & $?$ \\
\hline Williams $1865^{29}$ & 37 & 49 & - & - & 35 & 5 months \\
\hline Radcliffe $1866^{25}$ & 5 or 6 & 100 & 33 or 40 & - & - & $?$ \\
\hline Clouston $1868^{39}$ & 29 & 0 & 0 & 83 & 17 & 38 weeks \\
\hline Echeverria $1870^{40}$ & 416 & $?$ & - & - & 24 & $?$ \\
\hline Hammond $|87|^{41}$ & 286 & $?$ & 31.4 & 53 & 15 & $?$ \\
\hline Voisin $1873^{12}$ & 96 & $?$ & 21 & 56 & 23 & $6-9$ years \\
\hline Otto $1875^{42}$ & 33 & 3 or 6 & 48 & - & - & 8 months $^{*}$ \\
\hline Bennett $1884^{43}$ & 300 & $?$ & 12 & 83 & 5 & $?$ \\
\hline Turner $1903^{44}$ & 147 & $?$ & 26 & 29 & 45 & 9 years \\
\hline
\end{tabular}

potassium bromide to treat 14 or 15 women with menstruation-related emotional disturbance, at least two of whom also had epilepsy (and with failure to achieve seizure control in one of them) and he was either misunderstood by the reporters, or somehow misled them in the way he stated his results. Or perhaps the reporter(s) imposed a more restrictive interpretation of 'hysterical epilepsy' than Locock intended.

How did Locock obtain such a high control rate for seizures?

Table I shows published data on seizure control rates associated with bromide use during the half-century following 1857. After 1870, the figures include patients treated with bromide salts with bases other than potassium, including sodium, lithium and ammonium. In no series was the seizure control rate as high as the $93 \%$ reportedly obtained by Locock. Wilks recognised that short-term follow-up might allow treatments that failed in the longer term to be regarded as successful because they were associated with apparent early stage seizure control. ${ }^{23}$ Locock's treatment failure rate might have been the result of short periods of follow-up.
Considering the above points and Sieveking's apparent failure to comment immediately on Locock's therapeutic result (or the reporter[s] failure to mention such comments), Sieveking probably either suspected Locock's reported result or interpreted it differently to the reporters. Locock was responsible for making the medical profession aware of the antiepileptic efficacy of potassium bromide through the probable agency of some anonymous reporter(s). The critical issue is if his data really were as reported and that they may have led to unrealistic expectations in the medical profession. From the point of view of his future reputation, Locock may have been fortunate in announcing his results when he did, in the way he did, never committing them to print and in having Wilks provide good quality supporting evidence. Wilks was never eager to claim the original medical discovery for himself, though he zealously claimed it for an earlier generation of Guy's Hospital men, in particular Bright,Addison and Hodgkin. ${ }^{38}$ Perhaps Wilks was being unduly modest when he observed that his I86I paper had merely increased the medical profession's use of potassium bromide. ${ }^{24}$ It continued to be used for more than 150 years. 


\section{REFERENCES}

I Lennox WG. The centenary of bromides. N Engl J Med 1957; 256:887-90. http://dx.doi.org//0.1056/NEJMI9570509256/905

2 Scott DF. The history of epileptic therapy. Carnforth \& New York: Parthenon Publishing; 1993.

3 Friedlander WJ.The rise and fall of bromide therapy in epilepsy. Arch Neurol 2000;57: 1782-5.http://dx.doi.org//0.1001/archneur.57.12.1782

4 Pearce JM. Bromide, the first effective antiepileptic agent. J Neurol Neurosurg Psychiatry 2002; 72:4I2. http://dx.doi.org/I0.II36/ innp.72.3.4I2

5 Obituary. Sir Charles Locock, Bart. The Lancet I875; 106:184-5. http://dx.doi.org/I0.1016/S0I40-6736(02)30467-7

6 Obituary. Sir Charles Locock, Bart., M.D., D.C.L., F.R.S. Br Med J I875; ii:I5I.

7 Maulitz RC. Metropolitan medicine and the man-midwife: the early life and letters of Charles Locock. Med Hist 1982; 26:25-46.

8 Bettany GT (revised Digby A). Oxford dictionary of national biography. Oxford: Oxford University Press; 2004.

9 Locock C. Discussion of paper by EH Sieveking. Analysis of fiftytwo cases of epilepsy observed by the author. The Lancet 1857; 69:527-8.

10 Locock C. Discussion of paper by Dr Sieveking: analysis of fiftytwo cases of epilepsy observed by the author. Medical Times and Gazette 1857; 1:524-6.

II Laségue $C$. [Recherches nouvelles sur l'action thérapeutique du brome et de ses composés. Arch Gén de Méd 1865;6:8I-96. French.

12 Voisin A. Étude historique et thérapeutique sur le bromure de potassium.] Arch Gén de Méd 1873;21:35-53. French.

I3 Huette C. [Recherches sur les propriétés physiologiques et therapeutique du bromure de potassium] [thesis]. Paris: I859. French.

I4 Graf O. [De kali bromati efficacitate interna experimentis illustrate] [thesis]. Leipzig: 1842. German.

I5 Thielmann DR. [Action sédative du bromure de potassium sur les organes de la génération.] Gazette Hebdomadaire de Medecine et de Chirurgie 1853; I:44I-2. French.

16 Gowers WR. Epilepsy and other chronic convulsive diseases: their causes, symptoms and treatment. 2nd ed. London: J\&A Churchill; 1901.

17 Todd RB. Clinical lectures on paralysis, disease of the brain, and other affections of the nervous system. Philadelphia: Lindsay \& Blakiston; 1855.

I8 Sieveking EH. On epilepsy and epileptiform seizures. Their causes, pathology, and treatment. 2nd ed. London: John Churchill; I86I.

19 Radcliffe CB. Epilepsy and other convulsive affections: their pathology and treatment. 2nd ed. London: John Churchill; 1858.

20 Reynolds JR. Epilepsy: its symptoms, treatment and relation to other chronic convulsive diseases. London: John Churchill; I86I.

2I Woodbury DM. Bromides. In: Woodbury DM, Penry JK, Schmidt editors. RP antiepileptic drugs. Ist ed. New York: Raven Press; 1972.

22 Wilks S. Lectures on diseases of the nervous system. London: J\&A Churchill; 1878.

23 Wilks S. Bromide and iodide of potassium in epilepsy. Medical Times and Gazette 186I; 2:635-6.

24 Wilks S. Observations on the pathology of some of the diseases of the nervous system. Guy's Hospital Reports 1866; I2:157-244.
25 Radcliffe CB. Lectures on epilepsy, pain, paralysis and certain other disorders of the nervous system. Philadelphia: Blakiston Son \& Co.; 1866.

26 Radcliffe C. Gulstonian lectures for 1860. On the theory and therapeutics of convulsive diseases, especially of epilepsy. The Lancet 1860; 75:6I5-8.

27 Rogers GG. Epilepsy, and the administration of bromide of potassium. The Lancet 1864; 84:656-7. http://dx.doi.org//0.1016/ SOI40-6736(02)35255-3

28 M'Donnell R. Observations on the treatment of certain forms of epilepsy. Bromide of potassium. Dublin Quarterly Journal of Medical Science 1864; 37:43-50.

30 Brown-Séquard CE. The treatment of certain functional and organic affections of the nervous system. Chicago Medical Journal I866; 23:405-I4.

29 Williams SWD. On the action of the bromide of potassium. Journal of Mental Science 1865; 10:60I-7.

3I Bill JH. Experimental researches into the action and therapeutic value of bromide of potassium. The American Journal of the Medical Sciences 1868; 56:|7-3|.

32 Nothnagel H. Epilepsy and eclampsia. In: von Ziemssen H, editor. Cyclopaedia of the practice of medicine. New York:W Wood \& Co; 1877.

33 Reynolds JR. Epilepsy. In: Reynolds JR, editor. A system of medicine. Ist ed. Philadelphia: Henry C Lea's Son Co; 1880.

34 Charter and bye-laws of the Royal Medical and Chirurgical Society of London. Proceedings of the Royal Medical and Chirurgical Society of London 1857; I.

35 Sieveking EH. Analysis of fifty-two cases of epilepsy observed by the author. Med Chirug Trans 1857; 40:157-66.

36 Newmark ME, Penry JK. Catamenial epilepsy: a review. Epilepsia 1980; 21:28I-300. http://dx.doi.org/I0.IIII/j.I528-II57.1980. tb04074.x

37 Duncan S, Read CL, Brodie MJ. How common is catamenial epilepsy? Epilepsia 1993;34:827-3 I.http://dx.doi.org/I0.I I I I/j.I528-I I57.I993. tb02097.x

38 Wilks S. Historical notes on Bright's, Addison's, and Hodgkin's disease. Guy's Hosp Rep 1877; 22:259-74.

39 Clouston TS. Experiments to determine the precise effect of bromide of potassium in epilepsy. Journal of Mental Science 1868; |4:305-2l.

40 Echeverria MG. On epilepsy: anatomo-pathological and clinical notes. New York:Wood \& Co; 1870

4I Hammond, WA. A treatise on diseases of the nervous system. New York: Appleton \& Co; I87|

42 Otto A. [Ueber bromkalium als mittel gegen epilepsie]. European Archives of Psychiatry and Clinical Neuroscience 1875; 5:24-59. German.

43 BennettAH.An inquiry into the effects of the prolonged administration of the bromides in epilepsy. The Lancet 1884; 123:883-4; 928-30. http://dx.doi.org/I0.1016/S0|40-6736(02)/2707-3

44 Turner WA. A statistical enquiry into the prognosis and curability of epilepsy based upon the results of treatment. The Lancet 1903 I6I:I650-7. http://dx.doi.org/I0.1016/S0|40-6736(00)67842-X

45 Wilks S. A memoir. London: Adlard \& Son; 1911. 